\title{
Heterogeneous Expression of Claudin-4 in Human Colorectal Cancer: Decreased Claudin-4 Expression at the Invasive Front Correlates Cancer Invasion and Metastasis
}

\author{
Junya Ueda ${ }^{a}$ Shuho Semba ${ }^{a}$ Hideki Chiba $^{c}$ Norimasa Sawada ${ }^{c}$ Yasushi Seo $^{b}$ \\ Masato Kasuga $^{\mathrm{b}}$ Hiroshi Yokozaki $^{\mathrm{a}}$ \\ a Division of Surgical Pathology, Department of Biomedical Informatics, and bivision of Diabetes, Digestive and \\ Kidney Diseases, Department of Clinical Molecular Medicine, Kobe University Graduate School of Medicine, Kobe, \\ and ${ }^{C}$ Department of Pathology, Sapporo Medical University School of Medicine, Sapporo, Japan
}

\section{Key Words}

Claudin-4 $\cdot$ Colorectal cancer $\cdot$ Invasion $\cdot$ Metastasis

\begin{abstract}
Objective: Claudin-4 plays a key role in constructing the tight junction (TJ), and altered claudin-4 expression has been documented in various human malignancies; however, little is known about the biological significance of claudin- 4 in colorectal cancers (CRCs). The aim of this study is to investigate the significance of claudin- 4 expression in CRC and its association with clinicopathological factors. Methods: The levels of claudin- 4 expression in a total of 129 CRCs and 44 metastatic tumors were examined by immunohistochemistry. A small interfering RNA (siRNA)-mediated claudin-4 knockdown examination was also conducted to assess the biological role(s) of claudin-4 in cultured cells. Results: Expression of claudin- 4 at the intercellular membrane was well preserved at the surface of the tumor; however, decreased claudin-4 expression was detected in $57 \%$ of CRCs, particularly at the invasive front. Interestingly, decreased claudin-4 expression was detected in metastatic lesions of CRC. The siRNA-mediated claudin-4 knockdown in SW480 claudin-4positive CRC cells upregulated cell motility, whereas no significant change was detected in cell proliferation. Conclu-
\end{abstract}

\section{KARGER}

Fax +4161306 1234

E-Mail karger@karger.ch

www.karger.com (c) 2007 S. Karger AG, Basel

1015-2008/07/0741-0032\$23.50/0

Accessible online at:

www.karger.com/pat sions: These observations suggested that disruption of claudin-4-mediated TJ construction enhances cancer cell invasion and metastasis in human CRC. Claudin- 4 might be a good biomarker for diagnosing the risk of distant metastasis.

Copyright $\odot 2007$ S. Karger AG, Basel

\section{Introduction}

The invasive and metastatic activities of cancer cells are regulated by cell-to-cell adhesion and cell-to-extracellular matrix adhesion [1-5]. Among the numerous cell-to-cell adhesion apparatuses, tight junctions (TJs) have been revealed to regulate the invasive and metastatic potential of cancer cells [6-10]. TJs are located on the most apical side in the intercellular adherent structure of epithelial cells in the gastrointestinal tract [11]. Claudins are crucial components of TJs that play important roles in the formation of tightly connected cell sheets, the creation of physiologic barriers separating the apical and basolateral spaces, and the control of the permeability of electrolytes across a paracellular barrier via the formation of hetero- or homodimers [12-14]. Claudins bind to each other via two extracellular loops, and also bind to a 
PSD-95/Dscs-large/ZO-1 (PDZ)-domain-containing TJ protein, ZO-1, through their carboxyl terminus [15]. ZO-1 binds the TJ to the actin cytoskeleton and interacts with several cell signaling and transcriptional regulatory proteins; therefore, claudins are believed to play an important role in determining cell polarity through cytoskeleton rearrangement [16-19].

To date, about 24 claudins have been identified and many members of the claudin family show a distinct organ-specific distribution pattern within the human body $[12,16,20]$. Claudin- 4 was initially identified as a transmembrane receptor for Clostridium perfringens enterotoxin which binds to claudin-4 in epithelial cells of the intestinal tract with high affinity. As a result, small pores are formed in the cell membrane, which increases the cellular permeability and disrupts the balance of osmosis, ultimately destroying the cells [21]. Recently, some claudins have been associated with carcinogenesis and the progression of human malignancies [22-26]. In particular, altered levels of claudin- 4 at the mRNA and protein levels are likely to be associated with cancer development and progression; reduced claudin- 4 expression exhibited a close correlation with invasion and metastasis of human pancreas cancers, and overexpression of CLDN4 effectively diminished invasion and anchorage-independent growth in pancreas cancer cells [27]. These data suggested that decreased claudin- 4 expression may promote cancer cell invasion and metastasis in vitro and in vivo, as has been reported for claudin-3 and claudin-7 in several malignancies [28]. However, CLDN4 expression was frequently upregulated in ovarian tumors [22,29]; since little is known about the relationship between claudin- 4 expression and cancer progression, further investigation is required to understand the biological roles of claudin- 4 in human cancers. In this study, we analyzed the correlation between the levels of claudin-4 expression and clinicopathological findings in human CRC tissues. A small interfering RNA (siRNA)-mediated CLDN4 knockdown experiment was conducted to determine the biological significance of claudin- 4 expression in the progression of CRC cells.

\section{Materials and Methods}

Cell Lines and Tissue Samples

Five colon cancer cell lines (LoVo, TCO, DLD-1, WiDr, SW480) were maintained in RPMI-1640 (Invitrogen, Grand Island, N.Y., USA) supplemented with $1 \mathrm{mM} \mathrm{L-glutamine,} 10 \%$ fetal bovine serum (FBS; Invitrogen) and $1 \%$ antibiotic-antimycotic solution (Invitrogen). Cells were incubated at $37^{\circ} \mathrm{C}$ in humidified atmosphere of $95 \%$ air and $5 \% \mathrm{CO}_{2}$.

Claudin- 4 at the Invasive Front of Colorectal Cancer
Table 1. Variation in metastatic lesions in CRC patients analyzed in the primary tumor study

\begin{tabular}{lc}
\hline Primary tumors & Cases \\
\hline Total & 129 \\
No metastasis & 74 \\
Metastasis present $_{\quad \text { Lymph node }}^{\mathrm{a}}$ & 55 \\
$\quad$ Distant metastasis & 38 \\
$\quad$ Only liver & 4 \\
$\quad$ Only lung & 2 \\
$\quad$ Lung and dissemination & 1 \\
Lymph node ${ }^{\mathrm{a}}$ and distant metastasis & 1 \\
$\quad$ Lymph node and liver & 13 \\
$\quad$ Lymph node and dissemination & 9 \\
$\quad$ Lymph node, liver and lung & 1 \\
$\quad$ Lymph node, liver and dissemination & 2 \\
\hline
\end{tabular}

a Matched lymph node metastases were also confirmed by histological examination. Their claudin- 4 protein expression was also investigated.

$\mathrm{b}$ Tumors were diagnosed pathologically in the cases with surgical resection of metastasis or on imaging in the cases without surgical treatment.

Table 2. Variation in metastatic lesions in patients with CRC analyzed in the metastatic tumor study

\begin{tabular}{ll}
\hline Metastatic tumors & Cases \\
\hline Total & 44 \\
Only lymph node & 30 \\
Lymph node and liver & 6 \\
Lymph node, liver and lung & 3 \\
Lymph node and dissemination & 1 \\
Only liver & 3 \\
Only liver and lung & 1 \\
\hline
\end{tabular}

a Intra-abdominal and intra-thoracic lymph node metastases were confirmed by histological examination. Their expression of claudin-4 protein was also investigated.

In total, 129 cases of sporadic human CRCs surgically removed at Kobe University Hospital were studied. Formalin-fixed and paraffin-embedded specimens from 129 cases of primary CRC and from 44 cases of metastatic CRC were collected. Variation in the metastatic lesions of the CRC patients analyzed in this study is shown in tables 1 and 2. None of these cases had received adjuvant chemotherapy or radiotherapy before surgery, and informed consent was obtained from all patients. Histologic examination was performed according to the general rules of the Japanese Society for Cancer of the Colon and Rectum [30] and the classification of the International Union against Cancer [31].

Pathobiology 2007;74:32-41 
Reverse Transcription-Polymerase Chain Reaction (RT-PCR)

Total RNAs from each CRC cell line were isolated using a RNeasy Mini kit (Qiagen, Hilden, Germany). RT-PCR analysis was performed with a OneStep RT-PCR assay Kit (Qiagen) [32]. According to the poly(A) cDNA-specific RT-PCR method [33], the primer sets were designed as follows; CLDN4, 5'-GGACAGCTTCACCCTTGG-3'/5'-TTTTTTTTTTTTTTTCCTGTGCA- $3^{\prime}$, and $\beta$-actin, $5^{\prime}$-CCACGAAACTACCTTCAACTCC- $3^{\prime} / 5^{\prime}$ TCATACTCCT GCTGCTTGCTGATCC-3'. Each $25-\mu l$ reaction mixture containing $10 \mathrm{ng}$ of total RNA, $1 \mu \mathrm{M}$ of the primer pair and 0.75 units of reverse transcriptase and Taq DNA polymerase was amplified for 35 cycles using the following regimen: RT at $50^{\circ} \mathrm{C}$ for $30 \mathrm{~min}$; denaturation at $94^{\circ} \mathrm{C}$ for $30 \mathrm{~s}$; annealing at $58^{\circ} \mathrm{C}$ for $30 \mathrm{~s}$, and extension at $72^{\circ} \mathrm{C}$ for $1 \mathrm{~min}$. RT-PCR products were subjected to electrophoresis in $2 \%$ agarose gel.

\section{Western Blotting}

The cells were lysed in a buffer containing $50 \mathrm{mM}$ Tris- $\mathrm{HCl}$ (pH 7.4), $125 \mathrm{~mm} \mathrm{NaCl}, 0.1 \%$ Triton X-100 and 5 mM EDTA containing both $1 \%$ protease inhibitor (Sigma-Aldrich, St. Louis, Mo., USA) and 1\% phosphatase inhibitor cocktail II (Sigma-Aldrich) [32]. Proteins (40 $\mu$ g) were separated by sodium dodecyl sulfate polyacrylamide gel electrophoresis (SDS-PAGE) followed by electrotransfer onto polyvinylidene fluoride membranes (Millipore, Bedford, Mass., USA). Antisera against claudin-4 (Zymed, clone 3E2C1; San Francisco, Calif., USA) and anti- $\beta$-actin (Sigma-Aldrich) were used in the primary reaction. The specific reaction of anti-claudin- 4 antibody has been confirmed in previous reports $[22,29]$. Horseradish peroxidase-conjugated sheep antimouse IgG (Amersham Biosciences, Little Chalfont, UK) was used as a secondary antibody for an enhanced chemiluminescence reaction system (Immunostar Reagents; Wako, Osaka, Japan).

\section{siRNA Transfection Assay}

Human CLDN4-specific siRNA (5'-CGCACAGACAAGCCUUACUUU-3'/5'-AGUAAGGCUUGUCUGUGCGGG-3') was designed and based on the coding sequence of human CLDN4 [34]. Control (non-silence) siRNA (5'-UUCUCCGAACGUGUCACGUdTdT-3'/5'-ACGUGACACGUUCGGAGAAdTdT-3') was also synthesized. All of the siRNA sequences were subjected to a basic local alignment search tool to confirm the absence of homology to any additional known coding sequences in the human genome. Each siRNA was added to the SW480 cells $\left(4 \times 10^{4}\right.$ cells/well) in 24-well plates at a final concentration of $10 \mathrm{nM}$ using RNAiFect Transfection Reagent (Qiagen). Twenty-four hours after siRNA transfection, cells were incubated in RPMI-1640 plus $2 \%$ FBS. The medium was renewed every $48 \mathrm{~h}$. We confirmed that the transfection of CLND4 siRNA and control siRNA did not affect the levels of $\beta$-actin.

\section{Cell Motility Assay}

Cell motility and invasive activity were estimated using a modified two-chamber invasion assay with Transwell plates (6.4 $\mathrm{mm}$ in diameter; polyethylene terephthalate membrane, $8-\mu \mathrm{m}$ pore size) as described previously $[27,34]$. Twenty-four hours after siRNA transfection, an aliquot of $4 \times 10^{4}$ cells was placed in the upper chamber with $0.8 \mathrm{ml}$ of serum-free medium, whereas the lower chamber was loaded with $0.5 \mathrm{ml}$ of medium containing $10 \%$ FBS. Cells on the upper side of the membrane were wiped off, the membrane was fixed with $100 \%$ methanol and cells on the lower side of the membrane were counterstained with Mayer's hematoxylin. The cells that had migrated into the lower chamber were counted under a light microscope. Experiments were done in triplicate.

\section{Immunohistochemical Analysis}

Immunohistochemistry was performed using the streptavidin-biotin-peroxidase method with LSAB kit (DAKO, Carpinteria, Calif., USA) [32]. Briefly, deparaffinized and dehydrated 4$\mu \mathrm{m}$ sections were autoclaved in a citrate buffer $(\mathrm{pH}$ 6.0) for $15 \mathrm{~min}$ at $121^{\circ} \mathrm{C}$ to retrieve antigenicity. After blocking endogenous peroxidase with $0.3 \%$ hydroxyperoxide and nonspecific binding sites with 3\% BSA, anti-claudin-4 antibody (Zymed) was applied to the sections as the primary antibody and incubated. Subsequently, sections were incubated with biotinylated goat anti-mouse IgG and streptavidin conjugated to horseradish peroxidase. Chromogenic fixation was carried out by immersing the sections in a solution of 3,3-diaminobenzidine tetrahydrochloride. The sections were then counterstained with Mayer's hematoxylin.

Claudin-4 immunoreactivity was graded according to the number of stained cells and the staining intensity in individual cells as follows: $-=$ almost no positive cells; $+=5-50 \%$ of tumor cells showed weak immunoreactivity; $++=5-50 \%$ of tumor cells showed moderate immunoreactivity or $<30 \%$ of tumor cells showed intense immunoreactivity; $+++=>30 \%$ of tumor cells showed intense immunoreactivity [32]. Claudin-4 expression was evaluated independently by three independent observers (J.U., S.S., H.Y.) and all the sections were scored twice to confirm the reproducibility of the results.

\section{Statistical Analysis}

We used the $\chi^{2}$ test and the Mann-Whitey U test to evaluate relationships between claudin- 4 immunoreactivity and clincopathologic characters in 129 CRC cases. A p value $<0.05$ was considered statistically significant. Moreover, we used the log rank test to evaluate the relationship between claudin- 4 immunoreactivity and recurrence after surgical operation in 40 stage II CRCs which received neither adjuvant chemotherapy nor radiotherapy after the initial resection. Multivariate Cox analysis of recurrence was also performed.

\section{Results}

Downregulation of Claudin-4 at the Invasive Front and Metastatic Lesions of CRC Tissues

Immunohistochemical analysis was performed to investigate the expression of claudin- 4 in normal colorectal epithelia and CRC tissues. In normal colorectal epithelia, claudin-4 immunoreactivity was detected at the intercellular membrane of enterocytes and in the crypt epithelia specifically (fig. 1a, b). Table 3 summarizes the relationship between claudin-4 immunoreactivity at the invasive front and the clinicopathologic characteristics of the CRCs. Claudin-4 immunoreactivity tended to be well 
preserved in well-differentiated adenocarcinomas, but it tended to be decreased in both moderately and poorly differentiated adenocarcinomas $(p=0.00013$, fig. $1 c-e)$. Interestingly, the expression of claudin- 4 was heterogeneous; strong immunoreactivity of claudin- 4 was detected on the surface of CRC tissue, while claudin- 4 immunoreactivity was decreased at the invasive front and regions of vessel infiltration (fig. 1f-i). Furthermore, reduced claudin- 4 expression was significantly correlated with depth of invasion $(\mathrm{p}<0.0001)$, invasive pattern $(\mathrm{p}<$ $0.0001)$, lymphatic vessel invasion $(\mathrm{p}<0.0001)$, venous vessel infiltration $(\mathrm{p}=0.00011)$ and metastases [lymph nodes $(\mathrm{p}=0.00038)$, liver $(\mathrm{p}=0.013)$ and other distant organs $(\mathrm{p}=0.00079)]$.

We next examined claudin- 4 expression in 44 available cases of primary CRC at the invasive front and in their corresponding metastatic lesions. In comparison with the corresponding primary cancer tissues, claudin4 immunoreactivity of metastatic lesions was decreased in 30 cases $(68.1 \%, \mathrm{p}<0.0001$; table 4$)$. Representative illustrations of claudin- 4 immunohistochemistry in metastatic carcinoma of the liver and lymph nodes are shown in figure 2.

\section{Relationship between the Immunoreactivity of \\ Claudin-4 and Recurrence in Stage II CRC}

We further investigated the relationship between immunoreactivity of claudin- 4 and recurrence after surgical resection in 40 cases with stage II CRCs to confirm whether low claudin- 4 expression at the invasive front was a valuable prognostic indicator independent of clinical stage. The average observation period was 31 months. Although only 1 (9\%) of the 14 cases with high claudin- 4 expression showed recurrent carcinoma, there were as many as 7 (27\%) recurrent cases among the 26 cases with decreased claudin-4 expression. The patients with tumors that showed low claudin- 4 expression tended to have more frequent local recurrences $(\mathrm{p}=0.1795$; fig. $2 \mathrm{~g}$ ). Multivariate Cox analysis of local recurrence in stage II CRC revealed that cases with decreased claudin- 4 expression tended to have more recurrent tumors $(\mathrm{p}=0.1573)$ than those with high histological grade $(\mathrm{p}=0.2218)$ or vessel invasion $(\mathrm{p}=$ 0.8598 ); however, no statistical significance was found.

\section{Downregulation of Claudin-4 Expression Effectively \\ Promoted Cancer Cell Motility}

We investigated claudin-4 expression at the mRNA and protein levels in five CRC cell lines. Although CLDN4 expression was almost equivalent in these lines, claudin- 4 was expressed at a different level in each CRC

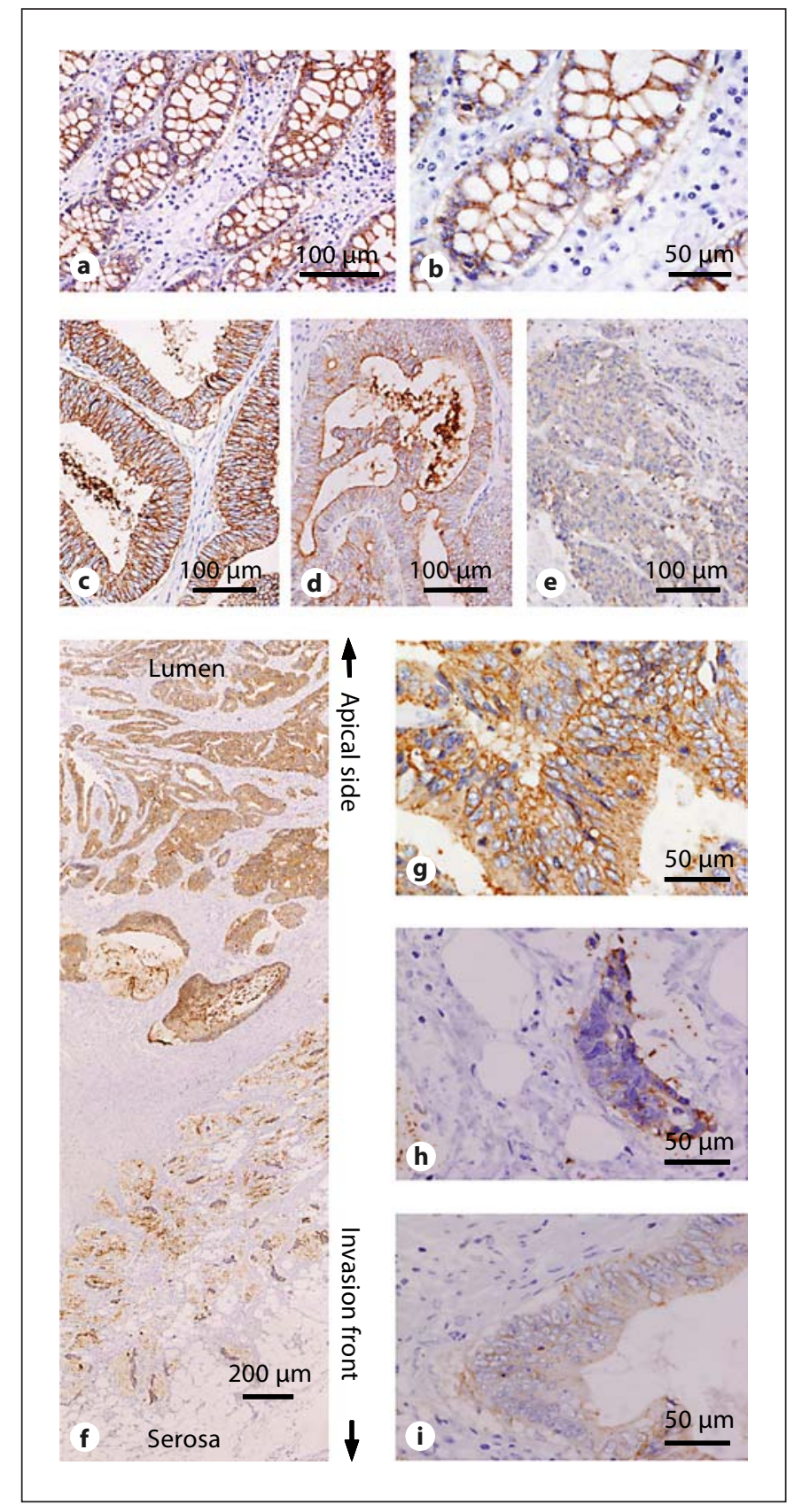

Fig. 1. Reduced expression of claudin-4 at the invasive front of human colon cancer tissues. a, b Expression of claudin- 4 in normal colon epithelia. Membranous localization of claudin-4 was detected. a $\times 200$. $\mathbf{b} \times 400$. c-e Claudin -4 immunoreactivity was correlated with histological type. c Well-differentiated type $(\times 200)$. d Moderately differentiated type $(\times 200)$. e Poorly differentiated type $(\times 200)$. $\mathbf{f}-\mathbf{i}$ Representative illustration of heterogenous expression of claudin- 4 in colon cancer tissue sample. Expression of claudin-4 was well-preserved at the tumor surface but decreased at the invasive front of colon cancer cells. $f$ Low magnification of the tumor $(\times 40)$. $\mathbf{g}$ Cancer cells at the surface $(\times 400)$. $\mathbf{h}$ Cancer cells at the invasive front $(\times 400)$. $\mathbf{i}$ Cancer cells showing lymphatic vessel infiltration $(\times 400)$. 
Table 3. Relationship between claudin-4 immunoreactivity and clinicopathologic characters of CRC

\begin{tabular}{|c|c|c|c|c|c|c|c|}
\hline & \multicolumn{2}{|c|}{ Cases } & \multicolumn{4}{|c|}{ Claudin-4 expression ${ }^{\mathrm{a}}$} & \multirow[t]{3}{*}{$\mathrm{p}$ value $\mathrm{e}^{\mathrm{b}}$} \\
\hline & \multirow[b]{2}{*}{$\mathrm{n}$} & \multirow[b]{2}{*}{$\%$} & \multicolumn{2}{|c|}{+++} & \multicolumn{2}{|c|}{+++ to -} & \\
\hline & & & $\mathrm{n}$ & $\%$ & $\mathrm{n}$ & $\%$ & \\
\hline Total & 129 & 100 & 55 & 43 & 74 & 57 & \\
\hline \multicolumn{8}{|l|}{ Sex } \\
\hline Male & 85 & 66 & 33 & 26 & 52 & 40 & \\
\hline Female & 44 & 34 & 22 & 17 & 22 & 17 & 0.22 \\
\hline \multicolumn{8}{|l|}{ Location } \\
\hline Right side of the colon & 42 & 33 & 18 & 14 & 24 & 19 & \\
\hline Left side of the colon & 87 & 67 & 37 & 29 & 50 & 38 & 0.97 \\
\hline \multicolumn{8}{|l|}{ Histologyc } \\
\hline Well differentiated & 43 & 33 & 30 & 23 & 13 & 10 & \\
\hline Moderate & 82 & 64 & 25 & 20 & 57 & 44 & \\
\hline Poor or mucinous & 4 & 3 & 0 & 0 & 4 & 3 & 0.00013 \\
\hline \multicolumn{8}{|l|}{ Depth of invasion } \\
\hline $\mathrm{m}$ & 11 & 9 & 11 & 9 & 0 & 0 & \\
\hline $\mathrm{sm}$ or $\mathrm{mp}$ & 30 & 23 & 20 & 15 & 10 & 8 & \\
\hline ss, se, a1 or a 2 & 83 & 64 & 24 & 19 & 59 & 45 & \\
\hline si & 5 & 4 & 0 & 0 & 5 & 4 & $<0.0001$ \\
\hline \multicolumn{8}{|l|}{ Invasion pattern } \\
\hline$\alpha$ (expansive) & 17 & 13 & 15 & 12 & 2 & 1 & \\
\hline$\beta$ (intermediate) & 51 & 40 & 30 & 23 & 21 & 17 & \\
\hline$\gamma$ (infiltrative) & 61 & 47 & 10 & 8 & 51 & 39 & $<0.0001$ \\
\hline \multicolumn{8}{|l|}{ Vessel infiltration } \\
\hline \multicolumn{8}{|l|}{ Lymphatic vessels } \\
\hline Positive & 99 & 77 & 32 & 25 & 67 & 52 & \\
\hline Negative & 30 & 23 & 23 & 18 & 7 & 5 & $<0.0001$ \\
\hline \multicolumn{8}{|l|}{ Venous vessels } \\
\hline Positive & 83 & 64 & 25 & 19 & 58 & 45 & \\
\hline Negative & 46 & 36 & 30 & 24 & 16 & 12 & 0.00011 \\
\hline \multicolumn{8}{|l|}{ Metastasis } \\
\hline \multicolumn{8}{|l|}{ Lymph node } \\
\hline Positive & 51 & 40 & 12 & 10 & 39 & 30 & \\
\hline Negative & 78 & 60 & 43 & 33 & 35 & 27 & 0.00038 \\
\hline \multicolumn{8}{|l|}{ Liver } \\
\hline Positive & 23 & 18 & 4 & 3 & 19 & 15 & \\
\hline Negative & 106 & 82 & 51 & 40 & 55 & 42 & 0.013 \\
\hline \multicolumn{8}{|l|}{ Metastatic organs } \\
\hline Positive & 29 & 22 & 4 & 3 & 25 & 19 & \\
\hline Negative & 100 & 78 & 51 & 40 & 49 & 38 & 0.00079 \\
\hline
\end{tabular}

The mean age of the cases was 68.1 years $(73.3$ and 57.8 for cases of +++ and ++ to claudin expression; $\mathrm{p}<0.018$ ).

${ }^{\text {a }}$ The expression of claudin- 4 was evaluated as described in Materials and Methods.

${ }^{b}$ Statistical analyses were performed by $\chi^{2}$ test and Mann-Whitney U test. A p value $<0.05$ was considered statistically significant.

${ }^{\mathrm{c}}$ Histological classification and clinicopathological staging were performed according to previously established rules [30]. line (fig. 3a, b). We confirmed that TCO cells showed prominent membrane immunoreactivity for claudin-4, while the membranous immunoreactivity was faint in SW480 cells (data not shown). To clarify the biological role of claudin- 4 in the invasive properties of CRC cells, we carried out an siRNA-mediated knockdown of CLDN4 expression in SW480 cells. The siRNA knockdown examination specifically suppressed claudin-4 protein expression at a concentration of $10 \mathrm{nM}$, but there was no significant difference in cell proliferation in the presence 


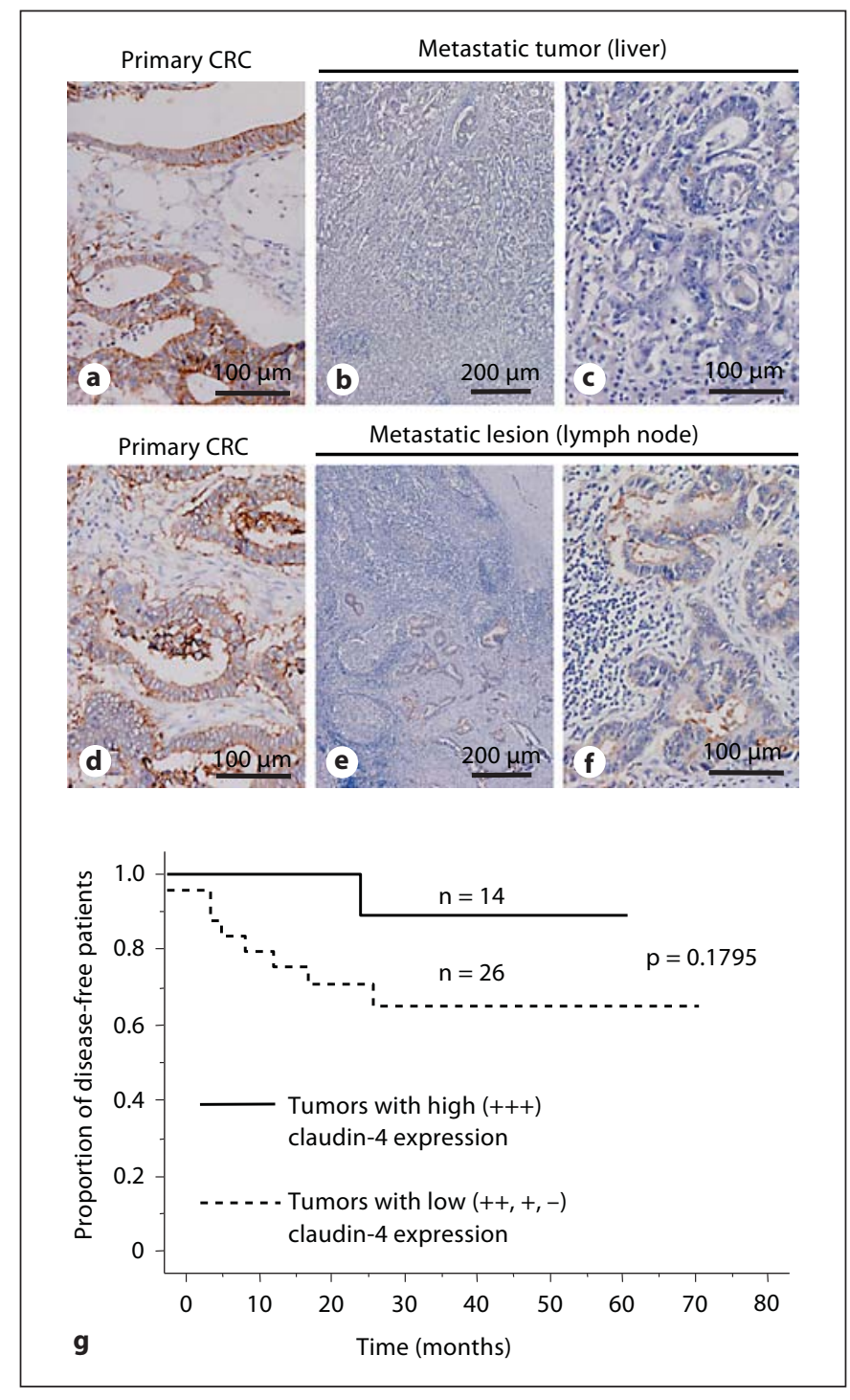

Fig. 2. Expression of claudin- 4 in metastatic lesions of human colon cancer. Representative results of immunohistochemical analysis. a-c Primary colon cancer $(\mathbf{a}, \times 200)$ and liver metastasis (b, $\times 40 ; \mathbf{c}, \times 200)$. d-f Primary colon cancer $(\mathbf{d}, \times 200)$ and lymph node metastasis $(\mathbf{e}, \times 40 ; \mathbf{f}, \times 200)$. g Kaplan-Meier disease-free analysis curves in stage II CRC for claudin- 4 expression. Although no statistical difference was detected $(p=0.01796)$, the patients with tumors that showed a low level of claudin- 4 tended to have a poorer prognosis. or absence of CLDN4 siRNA transfection (fig. 3c). However, CLDN4 knockdown in SW480 cells resulted in significantly greater cell motility than was seen in the cells transfected with control siRNA ( $p=0.0037$; fig. $3 \mathrm{~d}$ ).

\section{Discussion}

Altered expression of claudins has been reported in several malignant tumors, including those of the ovary $[22,35,36]$, prostate [23], breast [24, 37], pancreas [25], colorectum $[26,38]$ and stomach [39] in comparison with the corresponding normal tissues; however, little is known about the mechanism through which claudins control cancer cell behavior. A previous study reported that $75 \%$ of the stage II CRCs exhibited elevated levels of claudin-1 expression, while decreased claudin-1 expression was directly associated with higher tumor grade, recurrence and poor survival [26]. In addition, frequent nuclear localization of claudin-1 was reported in colon carcinoma tissues and cancer cell lines [40]; overexpression of claudin-1 in CRC cell lines induced structural and functional changes in markers of epithelial-mesenchymal transition and had significant effects on the growth of xenografted tumors and metastases in mice [40]. Ecadherin and $\beta$-catenin/Tcf signaling is considered to be a possible mechanism underlying claudin-1-dependent changes [41]. Furthermore, it has been documented that loss of claudin-7 expression correlates with histological grade in both ductal carcinoma in situ and invasive ductal carcinoma of the breast, occurring predominantly in high-grade (Nuclear and Elston grade 3) lesions [24]. In esophageal cancer, reduced expression of claudin-7 at the invasive front was significantly associated with the depth of invasion, clinicopathological stage, lymphatic vessel invasion and lymph node metastasis, suggesting that downregulation of claudin-7 at the invasive front of esophageal cancer may lead to tumor progression and subsequent metastatic events [42]. However, further investigation is required for the clarification of the biological role of claudins in human cancer.
Table 4. Claudin-4 expression of primary and metastatic lesions in CRC cases

\begin{tabular}{lllllll}
\hline & Total & \multicolumn{2}{l}{ Claudin-4 expression } & \multirow{2}{*}{ p value } \\
\cline { 3 - 6 } & & & + & ++ & +++ & \\
\hline Primary lesion & $44(100 \%)$ & $2(4.5)$ & $8(18.1)$ & $22(50)$ & $12(27.2)$ & \\
Metastatic lesion & $44(100 \%)$ & $9(20.4)$ & $25(56.8)$ & $7(15.9)$ & $3(6.8)$ & $<0.0001$ \\
\hline
\end{tabular}


a

Fig. 3. Downregulation of claudin-4 expression promotes cancer cell motility. a, b Expression of claudin-4 in cultured CRC cells at mRNA (a) and protein level (b). c, d siRNA-mediated knockdown of CLDN4 promoted cell motility. c The effect of CLDN4 siRNA on SW480 cell growth. No significant change in cell growth was detected in the presence or absence of CLDN4 siRNA transfection. CLDN4 siRNA specifically suppressed claudin-4 expression (left upper corner). d Results of cell migration assay. Downregulation of CLDN4 effectively promoted cell migration in SW480 cells ( $p=0.0037)$. - = Number of cancer cells migrating in a unit area; $\bigcirc=$ mean of migrating cells.

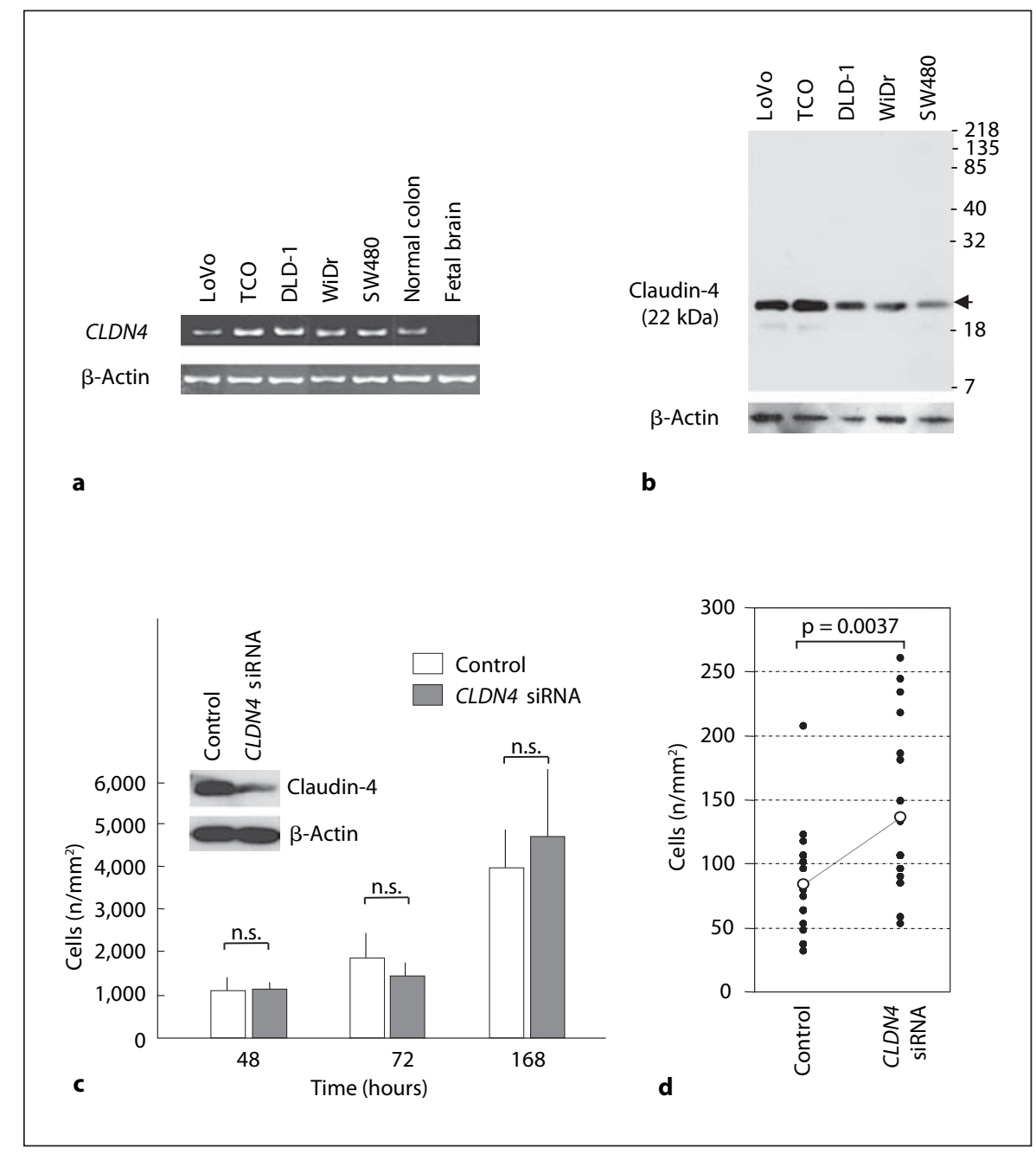

To our knowledge, this is the first report to show heterogeneous expression of claudin- 4 at the surface and invasive front of the same CRC tissue sample. The results demonstrated that low claudin- 4 expression contributed to CRC progression, histological grade, metastasis and poor prognosis, which is consistent with the results of examinations for pancreas cancer cells $[25,27]$. In a previous study using tissue microarray (TMA) technology [26], no significant association was found between claudin- 4 expression and any of the clinicopathological factors examined. The TMA method is valuable for comprehensive experiments that include many tissue samples. However, in the TMA, only a small region of each tissue sample is evaluated; TMA may thus be unsuitable for detailed evaluations of individual samples, such as heterogeneous expression patterns. However, intense positive claudin-4 immunolabeling is noted within virtually all primary and metastatic pancreatic cancers and pancreatic intraepithelial neoplasias with a membranous distribution [25], and overexpression of claudin- 4 has also been reported to suppress the growth, invasion and metastasis of pancreas cancer cells [27]. Conversely, increased levels of claudin- 4 expression have also been reported in the majority of ovarian carcinomas and shown to be closely associated with the grade of malignancy [22]. These observations suggest that claudin- 4 may play different roles in cancers originating from different organs. In the present study, mislocalization or weak membranous expression of claudin- 4 was observed in CRC cell lines and tissue samples containing precancerous lesions (data not shown). Such expression was not detected in normal epithelial tissues, suggesting that an alteration in the distribution of the claudin- 4 protein may be the key to CRC progression. The CLDN4 knockdown experiment 
performed in this study confirmed that suppression of membranous claudin-4 expression in SW480 cells promoted the invasion of CRC cells. While SW480 cells transfected with siRNA CLDN4 showed migration to various degrees, the mean of them was significantly increased compared to control. Further investigation using site-directed mutagenesis within the crucial domain for membranous claudin- 4 distribution including the changes in TJ structure and functionality is required to clarify the biological significance of claudin- 4 distribution in cancer cell progression.

Since claudin family members are crucial components of TJ, alterations in claudin- 4 expression may affect permeability at TJs, possibly increasing the diffusion of nutrients and other extracellular growth factors to promote cell growth and survival [17]. Thus, dysfunction of cellto-cell contact at the TJ may activate cell proliferation and motility even in cancer cells $[18,19,43]$. In this study, poorly differentiated adenocarcinomas exhibited lower levels of claudin- 4 than well-differentiated adenocarcinomas, suggesting that disruption of claudin-4-mediated TJ may allow increased diffusion of nutrients and other extracellular signaling stimulators in poorly differentiated carcinomas [44]. CLDN4 gene silencing by promoter hypermethylation has been found in bladder cancer [45] and ovarian cancer [46], and CLDN7 gene silencing by promoter methylation has been found in breast cancer cells [24]. To evaluate the mechanism by which CLDN4 expression is downregulated during the process of colorectal carcinogenesis, further investigations are needed on the status of promoter methylation of the CLDN4 gene or allelic deletion at the CLDN4 locus (7q11.23).

It has been proposed that inhibition of mitogen-activated protein kinase (MAPK) and phosphatidylinositol 3-OH kinase (PI3K) signaling by specific inhibitors re- sults in a decrease in claudin- 4 expression [27, 47]. Since the MAPK pathway has been reported to activate cell migration and motility by activating Rho and integrin family members $[48,49]$, claudin-4 may affect MAPK-Rhomodulated cell motility. The PI3K-Akt signaling pathway plays a pivotal role not only in cancer cell survival but also in cell polarity or differentiation [50-52], and activation of PI3K-Akt signaling is a common event in almost all human malignancies [53-55]. The concentrations of epidermal growth factor and $\mathrm{Ca}^{2+}$ have been reported to regulate claudin-4 expression in MDCK normal dog kidney cells [56]. Escape from these claudin-4 regulators may allow the cells to come into contact with extracellular nutrients and growth factors, resulting in the promotion of cell transformation in the multistep process of carcinogenesis of the colorectum.

The present results suggest that decreased claudin- 4 expression at the invasive front of CRC may be one of the important predictors of disease recurrence, and thus it may be necessary to strictly follow up not only stage II CRCs but all cases of low claudin- 4 expression at the invasive front after a curative operation. Although the mechanism responsible for low claudin- 4 expression in CRCs is still under investigation, this report unequivocally identifies claudin- 4 as a biomarker in CRCs. Further investigation into the regulation of claudin- 4 expression might characterize particular groups of patients who could benefit from a possible $C$. perfringens enterotoxinbased anticancer therapy targeting claudin- 4 .

\section{Acknowledgments}

This work was supported in part by a Grant-in-Aid for Cancer Research from the Ministry of Health, Labor and Welfare of Japan (14-8) and by the Terry Fox Foundation for Cancer Research.

\section{References}

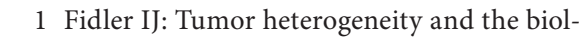
ogy of cancer invasion and metastasis. Cancer Res 1978;38:2651-2660.

2 Michelson S, Leith JT: Host response in tumor growth and progression. Invasion $\mathrm{Me}-$ tastasis 1996;16:235-246.

-3 Kemperman H, Driessens M, La Riviere G, Meijne AM, Roos E: The role of integrins and integrin activation in liver metastasis. Invasion Metastasis 1994;14:98-108.

4 Weiss L, Ward PM. Cell detachment and metastasis: Cancer Metastasis Rev 1983;2:111127.

Claudin- 4 at the Invasive Front of Colorectal Cancer
5 Hazan RB, Qiao R, Keren R, Badano I, Suyama K: Cadherin switch in tumor progression. Ann NY Acad Sci 2004;1014:155163.

-6 Christofori G: New signals from the invasive front. Nature 2006;441:444-450.

7 Behrens J, Frixen U, Schipper J, Weidner M, Birchmeier W: Cell adhesion in invasion and metastasis. Semin Cell Biol 1992;3:169-178.

8 Hannigan G, Troussard AA, Dedhar S: Integrin-linked kinase: a cancer therapeutic target unique among its ILK. Nat Rev Cancer 2005;5:51-63. $\checkmark 9$ Woodhouse EC, Chuaqui RF, Liotta LA: General mechanisms of metastasis. Cancer 1997;80:1529-1537.

10 Martin TA, Mansel RE, Jiang WG: Antagonistic effect of NK4 on HGF/SF induced changes in the transendothelial resistance (TER) and paracellular permeability of human vascular endothelial cells. J Cell Physiol 2002;192:268-275.

11 Tsukita S, Furuse M: Pores in the wall: claudins constitute tight junction strands containing aqueous pores. J Cell Biol 2000;149: 13-16. 
12 Morita K, Furuse M, Fujimoto K, Tukita S: Claudin multigene family encoding fourtransmembrane domain protein components of tight junction strands. Proc Natl Acad Sci USA 1999;96:511-516.

- 13 Chen Y, Lu Q, Schneeberger EE, Goodenough DA: Restoration of tight junction structure and barrier function by down-regulation of the mitogen-activated protein kinase pathway in ras-transformed MadinDarby canine kidney cells. Mol Biol Cell 2000;11:849-862.

14 Anderson JM: Molecular structure of tight junctions and their role in epithelial transport. News Physiol Sci 2001;16:126-130.

15 Itoh M, Furuse M, Morita K, Kubota K, Saitou M, Tsukita S: Direct binding of three tight junction-associated MAGUKs, ZO-1, $\mathrm{ZO}-2$, and $\mathrm{ZO}-3$, with the $\mathrm{COOH}$ termini of claudins. J Cell Biol 1999;147:1351-1363.

16 Tsukita S, Furuse M, Itoho M: Multifunctional strands in tight junctions. Nat Rev Mol Cell Biol 2001;2:285-293.

$\checkmark 17$ Mitic LL, Anderson JM: Molecular architecture of tight junctions. Annu Rev Physiol 1998;60:121-142.

18 Balda MS, Matter K: The tight junction protein ZO-1 and an interacting transcription factor regulate ErbB-2 expression. EMBO J 2000;19:2024-2033.

$\checkmark 19$ Fanning AS, Jameson BJ, Jesaitis LA, Anderson JM: The tight junction protein $\mathrm{ZO}-1$ establishes a link between the transmembrane protein occludin and the actin cytoskeleton. J Biol Chem 1998;273:29745-29753.

20 Rahner C, Mitic LL, Anderson JM: Heterogeneity in expression and subcellular localization of claudins $2,3,4$, and 5 in the rat liver, pancreas, and gut. Gastroenterology 2001;120:411-422.

-21 Katahira J, Inoue N, Horiguchi Y, Matsuda $\mathrm{M}$, Sugimoto N: Molecular cloning and functional characterization of the receptor for Clostridium perfringens enterotoxin. J Cell Biol 1997;136:1239-1247.

\22 Rangel LB, Agarwal R, D’Souza T, Pizer ES, Alo PL, Lancaster WD, Gregoire L, Schwartz DR, Cho KR, Morin PJ: Tight junction proteins claudin- 3 and claudin- 4 are frequently overexpressed in ovarian cancer but not in ovarian cystadenomas. Clin Cancer Res 2003;9:2567-2575.

-23 Long H, Crean CD, Lee WH, Cummings OW, Gabig TG: Expression of Clostridium perfringens enterotoxin receptors claudin-3 and claudin- 4 in prostate cancer epithelium. Cancer Res 2001;61:7878-7881.

24 Kominsky SL, Argani P, Korz D, Evron E, Raman V, Garrett E, Rein A, Sauter G, Kallioniemi OP, Sukumar S: Loss of the tight junction protein claudin-7 correlates with histological grade in both ductal carcinoma in situ and invasive ductal carcinoma of the breast. Oncogene 2003;22:2021-2033.
25 Nichols LS, Ashfaq R, Iacobuzio-Donahue CA: Claudin 4 protein expression in primary and metastatic pancreatic cancer: support for use as a therapeutic target. Am J Clin Pathol 2004;121:226-230.

26 Resnick MB, Konkin T, Routhier J, Sabo E, Pricolo VE: Claudin-1 is a strong prognostic indicator in stage II colonic cancer: a tissue microarray study. Mod Pathol 2005;18:511518.

27 Michl P, Barth C, Buchholz M, Lerch MM, Rolke M, Holzmann KH, Menke A, Fensterer H, Giehl K, Lohr M, Leder G, Iwamura T, Adler G, Gress TM: Claudin-4 expression decreases invasiveness and metastatic potential of pancreatic cancer. Cancer Res 2003 63:6265-6271.

28 Hewitt KJ, Agarwal R, Morin PJ: The claudin gene family: expression in normal and neoplastic tissues. BMC Cancer 2006;6:186.

29 Agarwal R, D’Souza T, Morin PJ: Claudin-3 and claudin-4 expression in ovarian epithelial cells enhances invasion and is associated with increased matrix metalloproteinase- 2 activity. Cancer Res 2005;65:7378-7385.

30 Japanese Society for Cancer of Colon and Rectum: General Rules for Clinical Pathological Studies on Cancer of the Colon, Rectum and Anus, ed 6. Tokyo, Kanehara, 1998.

31 Sobin LH, Wittekind CH: UICC TNM Classification of Malignant Tumors, ed 5. New York, Wiley, 1997.

32 Miskad UA, Semba S, Kato H, Yokozaki H: Expression of PRL-3 phosphatase in human gastric carcinomas: close correlation with invasion and metastasis. Pathobiology 2004; 71:176-184.

-33 Folz RJ, Nepluev I: Poly(A) cDNA-specific (PACS) RT-PCR: a quantitative method for the measurement of any poly (A)-containing mRNA not affected by contaminating genomic DNA. Biotechniques 2000;29:762768.

34 Mima S, Tsutsumi S, Ushijima H, Takeda M, Fukuda I, Yokomizo K, Suzuki K, Sano K, Nakanishi T, Tomisato W, Tsuchiya T, Mizushima T: Induction of claudin-4 by nonsteroidal anti-inflammatory drugs and its contribution to their chemopreventive effect. Cancer Res 2005;65:1868-1876.

- 35 Zhu Y, Brannstrom M, Janson PO, Sundfeldt $\mathrm{K}$ : Differences in expression patterns of the tight junction proteins, claudin 1, 3, 4 and 5, in human ovarian surface epithelium as compared to epithelia in inclusion cysts and epithelial ovarian tumours. Int J Cancer 2006;118:1884-1891.

36 Santin AD, Zhan F, Bellone S, Palmieri M, Cane S, Bignotti E, Anfossi S, Gokden M, Dunn D, Roman JJ, O’Brien TJ, Tian E, Cannon MJ, Shaughnessy J Jr, Pecorelli S: Gene expression profiles in primary ovarian serous papillary tumors and normal ovarian epithelium: identification of candidate molecular markers for ovarian cancer diagnosis and therapy. Int J Cancer 2004;112:14-25.
37 Hoevel T, Macek R, Swisshelm K, Kubbies M: Reexpression of the TJ protein CLDN1 induces apoptosis in breast tumor spheroids. Int J Cancer 2004; 108:374-383.

- 38 Aung PP, Mitani Y, Sanada Y, Nakayama H, Matsusaki K, Yasui W: Differential expression of claudin-2 in normal human tissues and gastrointestinal carcinomas. Virchows Arch 2006;448:428-434.

-39 Sanada Y, Oue N, Mitani Y, Yoshida K, Nakayama $\mathrm{H}$, Yasui W: Down-regulation of the claudin-18 gene, identified through serial analysis of gene expression data analysis, in gastric cancer with an intestinal phenotype. J Pathol 2006;208:633-642.

40 Dhawan P, Singh AB, Deane NG, No Y, Shiou SR, Schmidt C, Neff J, Washington MK, Beauchamp RD: Claudin-1 regulates cellular transformation and metastatic behavior in colon cancer. J Clin Invest 2005;115:17651776.

41 Medici D, Hay ED, Goodenogh DA: Cooperation between snail and LEF-1 transcription factors is essential for TGF- $\beta 1$-induced epithelial-mesenchymal transition. Mol Biol Cell 2006;17:1871-1879.

42 Usami Y, Chiba H, Nakayama F, Ueda J, Matsuda Y, Sawada N, Komori T, Ito A, Yokozaki $\mathrm{H}$ : Reduced expression of claudin-7 correlates with invasion and metastasis in squamous cell carcinoma of the esophagus. Hum Pathol 2006;37:569-577.

43 Polette M, Gilles C, Nawrocki-Raby B, Lohi J, Hunziker W, Foidart JM, Birembaut P: Membrane-type 1 matrix metalloproteinase expression is regulated by zonula occludens1 in human breast cancer cells. Cancer Res 2005;65:7691-7698.

44 Mullin JM: Potential interplay between luminal growth factors and increased tight junction permeability in epithelial carcinogenesis. J Exp Zool 1997;279:484-489.

45 Boireau S, Buchert M, Samuel MS, Pannequin J, Ryan JL, Choquet A, Chapuis H, Rebillard X, Avances C, Ernst M, Joubert D, Mottet N, Hollande F: DNA-methylationdependent alterations of claudin-4 expression in human bladder carcinoma. Carcinogenesis, E-pub ahead of print.

46 Honda H, Pazin MJ, Ji H, Wernyj RP, Morin PJ: Crucial roles of Sp1 and epigenetic modifications in the regulation of the CLDN4 promoter in ovarian cancer cells. J Biol Chem 2006;281:21433-21444.

47 Carrozzine F, Soulie P, Huber D, Mensi N, Orci L, Cano A, Feraille E, Montesano R: Inducible expression of Snail selectively increases paracellular ion permeability and differentially modulates tight junction proteins. Am J Physiol Cell Physiol 2005;89: C1002-C1014. 
48 Howe KL, Readon C, Wang A, Nazli A, McKay DM: Transforming growth factor-beta regulation of epithelial tight junction proteins enhances barrier function and blocks enterohemorrhagic Escherichia coli O157: H7-induced increased permeability. Am J Pathol 2005; 167:1587-1597.

49 Zondag GC, Evers EE, ten Klooster JP, Janssen L, van der Kammen RA, Collard JG: Oncogenic Ras downregulates Rac activity, which leads to increased Rho activity and epithelial-mesenchymal transition. J Cell Biol 2000;149:775-782.
50 Jo M, Thomas KS, Somlyo AV, Somlyo AP, Gonias SL: Cooperativity between the RasERK and Rho-Rho kinase pathways in urokinase-type plasminogen activator-stimulated cell migration. J Biol Chem 2002;277: 12479-12485.

51 Wodarz A: Tumor suppressors: linking cell polarity and growth control. Curr Biol 2000; 10:R624-R626.

52 Liu H, Radisky DC, Wang F, Bissell MJ: Polarity and proliferation are controlled by distinct signaling pathways downstream of PI3kinase in breast epithelial tumor cells. J Cell Biol 2004;164:603-612.

-53 Chung CY, Potikyan G, Firtel RA: Control of cell polarity and chemotaxis by Akt/PKB and PI3 kinase through the regulation of PAKa. Mol Cell 2001;7:937-947.
4 Waite KA, Eng C: Protean PTEN: form and function. Am J Hum Genet 2002;70:829844.

55 Itoh N, Semba S, Ito M, Takeda H, Kawata S, Yamakawa M: Phosphorylation of Akt/PKB is required for suppression of cancer cell apoptosis and tumor progression in human colorectal carcinoma. Cancer 2002;94:31273134.

56 Singh AB, Harris RC: Epidermal growth factor receptor activation differentially regulates claudin expression and enhances transepithelial resistance in Madin-Darby canine kidney cells. J Biol Chem 2004;279:35433552 . 